\title{
STANDARDISASI EKSTRAK BATANG GREGES OTOT (Equisentum debile Roxb.)
}

\author{
Nur Ermawati ${ }^{1}$ \\ ${ }^{1}$ Program Studi DIII Farmasi, Fakultas Farmasi, Universitas Pekalongan \\ Pekalongan \\ ${ }^{1}$ Email : nurermawati29@gmail.com \\ ARTICLE INFO : \\ Accepted \\ Approve \\ Publish
}

\begin{abstract}
Introduction, Equisentum debile Roxb. Has efficacy as an antidiarrheal, antihepatitis, rheumatism, inflammation of the eyes, and hemorrhoids. Objective,the purpose of this study was to standardize the stem of Equisentum debile Roxb. extract. Method, standardization of extracts is carried out with specific parameters consisting of: organoleptic; thin layer chromatography (TLC), and non-specific parameters consisting of: water content; specific gravity; and microbial contamination (total plate count). Result, the stem of Equisentum debile Roxb extract has the characteristics of thick green extract, aromatic distinctive odor and bitter taste. Based on chemical test shows that the positive extract contains flavonoids, alkaloids and saponins. Specific weight, water content and total microbial contamination of stems of Equisentum debile Roxb were $0.890 \mathrm{~g} / \mathrm{ml}, 10 \%, 1 \times 10^{4}$, respectively. Conclusion, the stem of Equisentum debile Roxb extracts have not met the overall standardization requirements.

Keywords : The stem of Equisentum debile Roxb extracts, Standardization, specific parameters, non-specific parameters
\end{abstract}

\begin{abstract}
ABSTRAK
Pendahuluan, tanaman greges otot (Equisentum debile Roxb.) memiliki khasiat sebagai antidiare, antihepatitis, rematik, inflamasimata, dan wasir. Tujuan, tujuan penelitian adalah untuk menstandarisasi ekstrak batang greges otot. Metode, standarisasi terhadap ekstrak dilakukan dengan parameter spesifik yang terdiri dari :organoleptis; kromatografi lapis tipis (KLT), dan parameter non spesifik yang terdiridari : kadar air; bobot jenis; dan cemaran mikroba (angka lempeng total). Hasil, ekstrak batang greges otot memiliki karakteristik ekstrak kental berwarna hijau, bau khas aromatik dan rasa pahit. Berdasarkan uji kandungan kimia menunjukkan bahwa ekstrak positif mengandung flavonoid, alkaloid dan saponin. Bobot jenis, kadar air dan total cemaran mikroba ekstrak batang batang greges otot berturut-turut adalah $0,890 \mathrm{~g} / \mathrm{ml} ; 10 \%$ $; 1 \times 10^{4}$. Kesimpulan, ekstrak batang greges otot belum memenuhi persyaratan standarisasi secara keseluruhan.
\end{abstract}

\section{Kata kunci : Batang greges otot, Standardisasi, Parameter spesifik, Parameter non spesifik}


PENDAHULUAN

Tanaman

greges otot

mengandung asam kersik, asam oksalat, asam malat, asam akonitat, asam tanat, kalium, natrium, thiaminase, dan saponin. Tanaman greges otot dapat berkhasiat untuk pengobatan patah tulang, hepatitis, radang mata, rematik dan wasir (Herbie,2015). Ekstrak greges otot memiliki aktivitas antihistamin dan antikolinergik (Ali dkk, 2017) dan sebagai antidiare (Abdillahdkk, 2018). Senyawa metabolit sekunder yang berkhasiat meningkatkan efek antidiare pada penelitian yang telah dilakukan adalah tanin dengan kadar sebanyak 19,17\%. Beberapa penelitian telah membuktikan khasiat tanaman greges otot sebagai bahan obat herbal, sementara ekstrak batang tanaman greges otot perlu dilakukan standardisasi ekstrak untuk menjamin konsistensi kualitas ekstrak apabila akan dikembangkan menjadi sediaan obat herbal terstandar, sebab batang greges otot belum banyak yang mengetahui khasiatnya. Standardisasi sebelumnya pernah dilakukan untuk penelitian khasiat namun tidak spesifik pada batangnya. Oleh karena itu penelitian ini dilakukan untuk dapat melengkapi data standardisasi ekstrak herbal khususnya batang greges otot.

\section{METODE PENELITIAN}

Penelitian ini menggunakan desain penelitian deskriptif kualitatif yang bertujuan untuk mengetahui standardisasi ekstrak batang greges otot.

\section{Bahan Penelitian}

Bahan yang digunakan dalam penelitian ini adalah tanaman greges otot yang diperoleh dari Kecamatan Semarang Barat. Bahan kimia yang digunakan adalah etanol 70\%, akuadest, butanol, asam asetat, etil asetat, metanol, kloroform (p.a. Merck), Nutrient Agar (PT. Brataco), pereaksi Dragendroff, pereaksi LibermanBurchard (Medissh), pereaksi $\mathrm{FeCl}_{3} 1 \%$ (Merk) .

\section{Alat Penelitian}

Alat yang digunakan dalam penelitian ini adalah magnetik stirer, beaker glass, oven, rotary vaccum evaporator, batang pengaduk, cawan porselen, neraca analitik, piknometer, pipet tetes $\left(\right.$ Pyrex $\left.^{\circledR}\right)$, cawan petri, pipa kapiler, gelas ukur (Pyrex ${ }^{\circledR}$ ), labu ukur (Pyrex $\left.{ }^{\circledR}\right), \quad$ bejana kromatografi $\left(\right.$ Canax $\left.^{\circledR}\right)$, silika gel $60 \mathrm{~F}_{245}$, sinar UV 254. 
Pembuatan Ekstrak Batang Greges Otot

Batang tanaman greges otot dipisahkan dari bagian lain dan dicuci bersih dengan air mengalir. Batang dikeringkan dalam oven dengan suhu $50^{\circ} \mathrm{C}$ dan dibuat dalam bentuk serbuk dengan cara di blender. Serbuk batang greges otot di maserasi dengan menggunakan penyari etanol $70 \%$ sebanyak 2 kali berat simplisisa atau sampai dapat merendam seluruh simplisia. Serbuk batang greges otot dimaserasi dalam larutan etanol $70 \%$ dan perendaman 6 jam pertama sekalisekali diaduk, diulang untuk 6 jam selanjutnya diaduk, kemudian diamkan selama 72 jam atau 3 hari. Campuran tersebut kemudian disaring diperoleh filtrat. Hasil filtrat yang diperoleh kemudian diuapkan menggunakan wather bath atau penangas airhingga pelarut etanol menguap dan sampai ekstrak kental yang diinginkan (Abdillah dkk, 2018).

Pengukuran Parameter Spesifik Ekstrak Batang Greges Otot

Penetapan sifat organoleptis ekstrak

Penetapan organoleptis dengan pengenalan secara fisik menggunakan panca indra dalam mendiskripsikan bentuk, warna, bau dan rasa.

\section{Penetapan kandungan senyawa aktif dengan kromatografi lapis tipis (KLT)}

Senyawa aktif seperti flavonoid, alkaloid dan saponin dalam ekstrak batang greges otot ditetapkan dengan metode KLT.

Flavonoid

Fase diam : Silika gel $F_{254}$

Fase gerak : Butanol-asam asetat-air $(4: 1: 5)$

Pembanding : Kuersetin

Deteksi : UV 254, UV 366, pereaksi semprot $\mathrm{FeCl}_{3}$

Alkaloid

Fase diam : Silika gel $F_{254}$

Fase gerak : Kloroform : metahol

$(9: 1)$

Pembanding : Kafein

Deteksi : UV 254, UV 366, pereaksi semprot Dragendroff

Saponin

Fase diam : Silika gel $\mathrm{F}_{254}$

Fase gerak : Kloroform-metanol-air $(5: 4: 1)$

Pembanding : Saponin

Deteksi : UV 254, UV 366, pereaksi Liberman-Burchard 
Pengukuran Parameter Non-Spesifik

Ekstrak Batang Greges Otot

Parameter non spesifik ekstrak

batang greges otot yang ditetapkan adalah kadar air, bobot jenis, cemaran mikroba angka lempeng total (ALT)

HASIL

Parameter Spesifik Ekstrak Batang Greges Otot

Tabel I. Hasil Uji Organoleptis

\begin{tabular}{ccccc}
\hline & \multicolumn{4}{c}{ Organoleptis } \\
\cline { 2 - 5 } Hasil & Bentuk & Warna & Rasa & Bau \\
\cline { 2 - 5 } Percobaan & Kental & Hijau & Pahit & Khas \\
& & & & aromatis \\
\hline
\end{tabular}

Tabel II. Hasil Identifikasi Senyawa Flavonoid

\begin{tabular}{|c|c|c|c|c|c|c|c|c|}
\hline Senyawa & Percobaan & $\begin{array}{c}\text { Standar } \\
\text { hasil } \\
\text { warna }\end{array}$ & $\begin{array}{c}\text { Sinar } \\
\text { visible }\end{array}$ & $\begin{array}{c}\text { Sinar } \\
\text { UV }_{254 n m}\end{array}$ & $\begin{array}{c}\text { Sinar } \\
\text { UV366nm }\end{array}$ & $\begin{array}{c}\text { Nilai } \\
\text { Rf }\end{array}$ & $\begin{array}{c}\text { Nilai } \\
\text { Rf } \\
\text { standar }\end{array}$ & Keterangan \\
\hline \multirow{4}{*}{ Flavonoid } & I & \multirow{4}{*}{$\begin{array}{c}\text { Hijau/ } \\
\text { kuning/ } \\
\text { biru }\end{array}$} & Hijau & Kuning & $\begin{array}{l}\text { Putih/ } \\
\text { biru }\end{array}$ & 0,35 & & \multirow{4}{*}{ Positif } \\
\hline & II & & Hijau & Kuning & $\begin{array}{l}\text { Putih/ } \\
\text { biru }\end{array}$ & 0,35 & & \\
\hline & III & & Hijau & Kuning & $\begin{array}{l}\text { Putih/ } \\
\text { biru }\end{array}$ & 0,35 & & \\
\hline & Kuersetin & & Hijau & $\begin{array}{c}\text { Kuning/ } \\
\text { hijau }\end{array}$ & $\begin{array}{l}\text { Putih/ } \\
\text { biru }\end{array}$ & $\begin{array}{l}0,35 \\
0,28\end{array}$ & 0,51 & \\
\hline
\end{tabular}




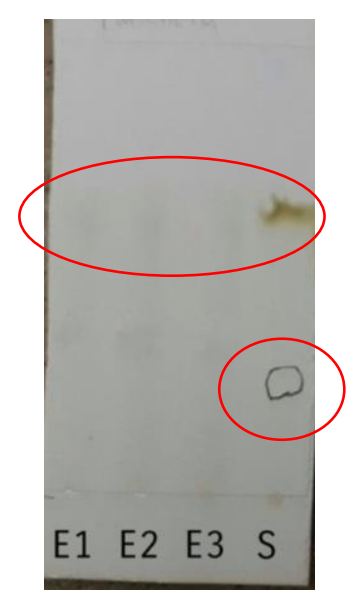

A

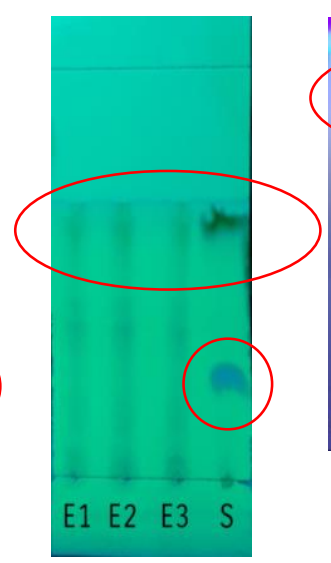

B

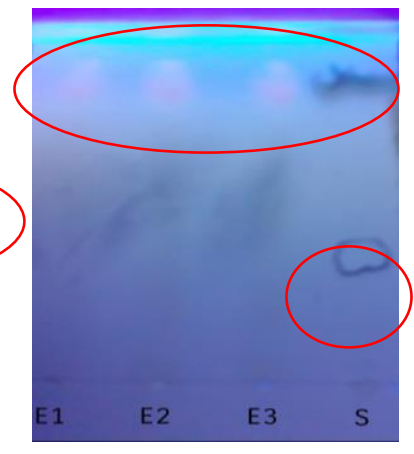

Gambar 1. Hasil identifikasi senyawa flavonoid Ekstrak dan Standar pada (A) Sinar visible (B) Sinar $\mathbf{U V}_{254 \mathrm{~nm}}$ (C) Sinar $\mathrm{UV}_{366 \mathrm{~nm}}$

Tabel III. Hasil Identifikasi Senyawa Alkaloid

\begin{tabular}{|c|c|c|c|c|c|c|c|c|}
\hline Senyawa & Percobaan & $\begin{array}{c}\text { Standar } \\
\text { hasil } \\
\text { warna }\end{array}$ & $\begin{array}{c}\text { Sinar } \\
\text { visible }\end{array}$ & $\begin{array}{c}\text { Sinar } \\
\mathrm{UV}_{254 \mathrm{~nm}}\end{array}$ & $\begin{array}{c}\text { Sinar } \\
\mathrm{UV}_{366 \mathrm{~nm}}\end{array}$ & $\begin{array}{l}\text { Nilai } \\
\text { Rf }\end{array}$ & $\begin{array}{c}\text { Nilai } \\
\text { Rf } \\
\text { standar }\end{array}$ & Keterangan \\
\hline \multirow{4}{*}{ Alakloid } & I & \multirow{4}{*}{$\begin{array}{c}\text { Ungu/ } \\
\text { floresensi } \\
\text { biru/ } \\
\text { coklat }\end{array}$} & Putih & Ungu & $\begin{array}{l}\text { Putih/ } \\
\text { biru }\end{array}$ & 0,28 & & \multirow{4}{*}{ Positif } \\
\hline & II & & Putih & Ungu & $\begin{array}{l}\text { Putih/ } \\
\text { biru }\end{array}$ & 0,28 & & \\
\hline & III & & - & - & - & - & & \\
\hline & Kafein & & Putih & Ungu & $\begin{array}{l}\text { Putih/ } \\
\text { biru }\end{array}$ & 0,28 & 0,26 & \\
\hline
\end{tabular}
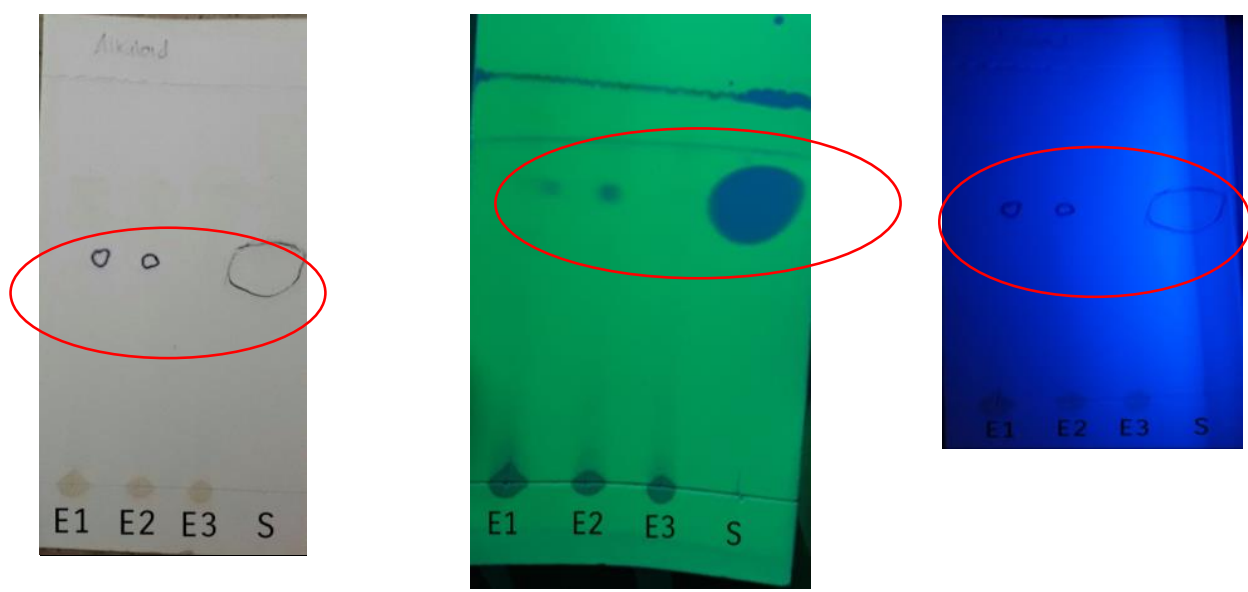
Gambar 2. Hasil identifikasi senyawa alkaloid Ekstrak dan Standar pada (A) Sinar visible (B) Sinar UV $254 \mathrm{~nm}$ (C) Sinar UV $366 \mathrm{~nm}$

Tabel IV. Hasil Identifikasi Senyawa Saponin

\begin{tabular}{|c|c|c|c|c|c|c|c|c|}
\hline Senyawa & Percobaan & $\begin{array}{c}\text { Standar } \\
\text { hasil warna }\end{array}$ & $\begin{array}{c}\text { Sinar } \\
\text { visible }\end{array}$ & $\begin{array}{c}\text { Sinar } \\
\mathrm{UV}_{254 \mathrm{~nm}}\end{array}$ & $\begin{array}{c}\text { Sinar } \\
\text { UV366nm }\end{array}$ & $\begin{array}{l}\text { Nilai } \\
\text { Rf }\end{array}$ & $\begin{array}{c}\text { Nilai } \\
\text { Rf } \\
\text { standar }\end{array}$ & Keterangan \\
\hline \multirow{4}{*}{ Saponin } & I & \multirow{4}{*}{$\begin{array}{c}\text { Ungu/ } \\
\text { pemadaman }\end{array}$} & Coklat & Ungu & Biru & 0,42 & & \multirow{4}{*}{ Positif } \\
\hline & II & & Coklat & Ungu & Biru & 0,41 & & \\
\hline & III & & - & - & - & - & & \\
\hline & Sapoin & & Coklat & Ungu & $\begin{array}{l}\text { Putih/ } \\
\text { biru }\end{array}$ & 0,38 & 0,38 & \\
\hline
\end{tabular}

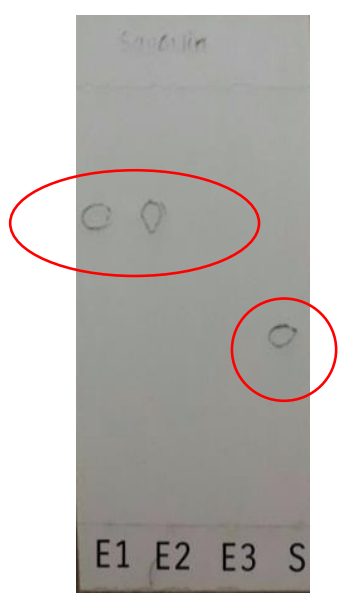

A

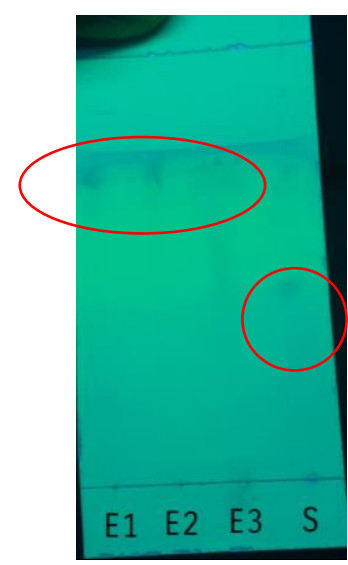

B

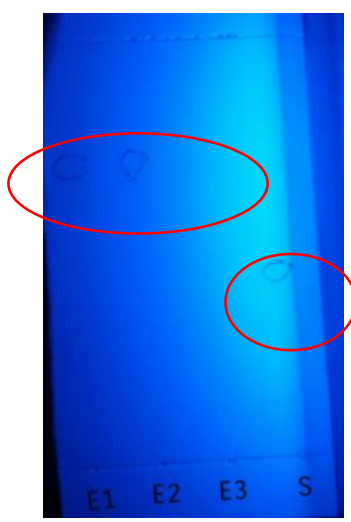

C

Gambar 3. Hasil identifikasi senyawa saponin ekstrak dan standar pada (A) Sinar visible (B) Sinar UV 254nm(C) Sinar UV 366nm

\section{Parameter Non-Spesifik}

\section{Tabel V. Hasil Pengukuran Parameter Non-Spesifik}

\begin{tabular}{ll}
\hline Parameter & Nilai \\
\hline Bobot Jenis & $0,890 \mathrm{~g} / \mathrm{mL}$ \\
Kadar Air & $10 \%$ \\
Cemaran MikrobaAngka Lempeng Total (ALT) & $>1 \times 10^{4}$ \\
\hline
\end{tabular}




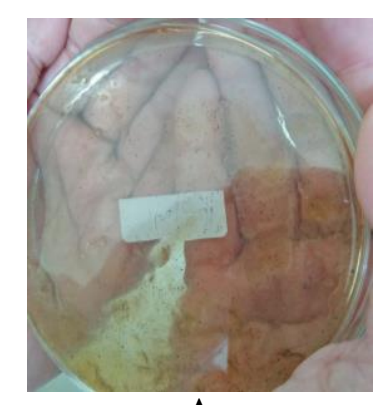

$\mathbf{A}$

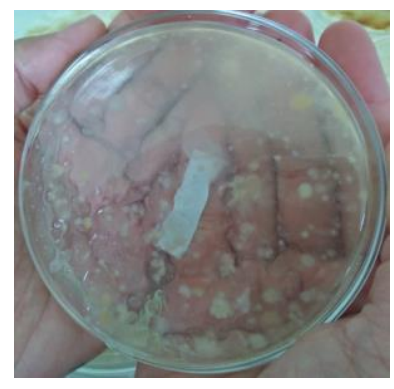

C

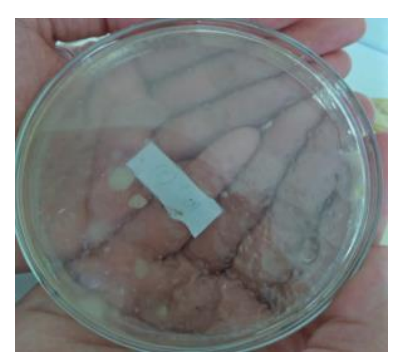

B

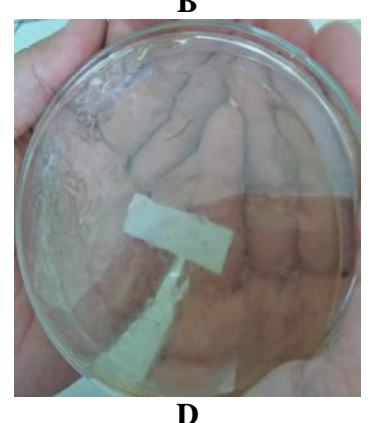

Gambar 4. Hasil identifikasi cemaran mikroba ALT(A) pengenceran $10^{-1}(B)$ pengenceran $10^{-2}(C)$ pengenceran $10^{-3}(\mathrm{D})$ kontrol negatif

\section{PEMBAHASAN}

Pada penelitian ini, digunakan sampel batang greges otot (Equisentum debile Roxb.). Batang greges otot dilakukan sortasi basah untuk memisahkan batang yang baik dan tidak baik atau tidak segar, setelah itu dicuci dengan air mengalir. Setelah itu batang dipotong untuk memperkecil ukuran dan mempermudah pengeringan, proses pengeringan untuk meminimalkan kandungan air batang greges otot sehingga dapat mengurangi resiko pertumbuhan mikroorganisme selama penyimpanan. Pada proses ekstraksi dilakukan dengan teknik maserasi menggunakan pelarut etanol $70 \%$. Proses maserasi terjadi akibat adanya perbedaan konsentrasi antara kandungan kimia di dalam sel batang yang disari dengan kandungan kimia yang berada diluar sel, pelarut akan masuk ke dalam sel pada batang dan karena ada perbedaan konsentrasi antara kandungan kimia di dalam sel dengan kandungan kimia yang berada di luar sel, kandungan kimia di dalam batang akan tersari oleh pelarut dan keluar dari dalam sel pada batang. Proses ekstraksi menggunakan serbuk batang greges otot sebanyak 500 gram, hasil ekstraksi diperoleh ekstrak kental sebanyak 36,3 gram. Presentase rendemen yang diperolah sebesar 7,26\%, besar kecilnya presentase rendemen menunjukkan keefektifan proses ekstraksi dipengaruhi oleh jenis pelarut yang digunakan. 
Pengujian senyawa aktif yang terdapat pada ekstrak batang greges otot dilakukan dengan metode kromatografi lapis tipis (KLT) yang bertujuan untuk memberikan gambaran awal komposisi kandungan kimia berdasarkan pola kromatografi. KLT merupakan teknik pemisahan campuran berdasarkan perbedaan distribusi dari komponen campuran tersebut diantara dua fase yaitu fase diam dan fase gerak. Pelarut atau fase gerak yang dipilih disesuaikan dengan sifat kelarutan senyawa yang dianalisis, sebagai fase diam digunakan silika gel $\mathrm{F}_{254}$ karena tidak bereaksi dengan senyawa atau pereaksi yang reaktif. Data yang diperoleh dari analisis dengan KLT adalah nilai Rf, ini berguna untuk identifikasi suatu senyawa.

Berdasarkan pengujian identifikasi senyawa flavonoid yang terlihat pada Gambar 1, adanya perbedaan penampakan bercak, pada $\mathrm{UV}_{254 \mathrm{~nm}}$ bercak berwarna hijau kekuningan dan $\mathrm{UV}_{366 \mathrm{~nm}}$ bersinar putih biru sesuai dengan Hanani (2016) bahwa flavonoid dapat berfluoresensi dan memberikan warna kuning, hijau, biru. Identifikasi senyawa KLT juga dilakukan dengan membandingkan nilai Rf ekstrak dengan senyawa pembanding. Senyawa flavonoid ekstrak batang greges otot memiliki nilai Rf 0,35 sedangkan kuersetin sebagai pembanding memiliki dua nilai Rf 0,35 dan 0,28, karena ada dua bercak yang terlihat pada sinar ini dikatakan pembanding yang digunakan memiliki warna yang berbeda pada monografi senyawa kuersetin sehingga warna yang muncul sudah terlihat sama serperti serbuk kuersetin standar baku yang ada, akan tetapi karena memunculkan dua bercak pada plat ini dipengaruhi oleh pelarutan serta alat gelas yang tercampur air. Nilai Rf ini memiliki perbedaan yang cukup besar antara ekstrak dengan pembanding kuersetin sedangkan nilai Rf pembanding kuersetin pada literatur 0,51 perbedaan cukup besar sekali sehingga hasil tersebut dapat dikatakan bahwa senyawa flavonoid terdapat pada ekstrak batang greges otot. Hasil dikatakan positif karena warna yang muncul pada plat hampir sama dengan pembanding maupun literatur, deteksi fitokimia disini hanya untuk mengetahu ada tidaknya senyawa flavonoid pada batang greges otot. Untuk perbedaan niali Rf yang dihasilkan berbeda cukup besar dari ekstrak, standar kuersetin maupun literatur ini dikarenakan pada 
batang greges otot menurut Ali dkk, 2017 tidak menyatakan adanya kuersetin didalam batang greges otot tetapi hanya ada senyawa flavonoid.

Berdasarkan pengujian identifikasi senyawa alkaloid yang terlihat pada Gambar 2 adanya perbedaan penampakan bercak, pada $\mathrm{UV}_{254 \mathrm{~nm}}$ menunjukkan bercak berwarna ungu sedangkan pada $\mathrm{UV}_{366 n m}$ tidak bersinar ini hampir tidak sesuai dengan Hanani (2016) bahwa dapat berfluoresensi dan memberikan warna ungu. Identifikasi senyawa KLT juga dilakukan dengan membandingkan nilai Rf ekstrak dengan senyawa pembanding kafein. Senyawa alkaloid ekstrak batang greges otot memiliki nilai $\mathrm{Rf} 0,28$ sedangkan kafein sebagai pembanding memiliki nilai $\operatorname{Rf} 0,28$. Nilai $\operatorname{Rf}$ ini memiliki persamaan antara ekstrak dengan pembanding kafein sedangkan nilai Rf pembanding kafein pada literatur 0,26 perbedaan tidak besar sekali sehingga hasil tersebut dapat dikatakan bahwa senyawa alkaloid terdapat pada ekstrak batang greges otot.

$$
\text { Berdasarkan pengujian }
$$
identifikasi senyawa yang terlihat pada Gambar 3 adanya perbedaan penampakan bercak, pada $\mathrm{UV}_{254 \mathrm{~nm}}$ menunjukkan warna bercak ungu untuk $\mathrm{UV}_{366 \mathrm{~nm}}$ bersinar kekuningan ini sesuai dengan Hanani (2016) bahwa dapat berfluoresensi dan memberikan warna ungu .Identifikasi senyawa KLT juga dilakukan dengan membandingkan nilai Rf ekstrak dengan senyawa pembanding saponin. Senyawa saponin ekstrak batang greges otot memiliki nilai $\mathrm{Rf}$ 0,42 sedangkan saponin sebagai pembanding memiliki nilai $\operatorname{Rf} 0,38$. Nilai Rf ini memiliki persamaan antara ekstrak dengan pembanding saponin sedangkan nilai Rf pembanding saponin pada literatur 0,38 perbedaan tidak besar sekali sehingga hasil tersebut dapat dikatakan bahwa senyawa saponin terdapat pada ekstrak batang greges otot.

Penentuan bobot jenis ditentukan dengan menggunakan piknometer. Ekstrak yang digunakan adalah ekstrak yang telah diencerkan dengan etanol $70 \%$ menjadi $5 \%$ dengan suhu $20^{\circ}$ C. Pengujian ini diperoleh bobot jenis ekstrak sebesar $0,890 \mathrm{~g} / \mathrm{ml}$. Hasil ini tidak dibandingkan dengan literatur dikarenakan setiap ekstrak tanaman memiliki perbedaan, dipengaruhi adanya pelarut etanol dengan bobot jenis $0,789 \mathrm{~g} / \mathrm{ml}$ dan air memiliki bobot jenis $0,897 \mathrm{~g} / \mathrm{ml}$ 
sehingga ini mempengaruhi bobot jenis ekstrak.

Penentuan kadar air bertujuan memberikan batas minimal atau rentang tentang besarnya kandungan air dalam ekstrak batang greges otot. Kadar air yang terdapatdalam ekstrak sebesar $10 \%$ hasil ini masuk dalam range standar mutu ekstrakyaitu 5\% - 30\% dapat dikatakan aman memiliki kadar air tersebut. Sehingga ekstrak tidak begitu mudah ditumbuhi mikroorganisme dan memiliki stabilitas yang cukup baik.

Pengujian cemaran mikroba angka lempeng total (ALT) merupakan salah satu pengujian untuk mengetahui kemurnian ekstrak. Pada pengenceran $10^{-1}$ hasil pengujian cemaran mikroba angka lempeng total yaitu $0 \times 10^{4}$ ini tidak memperlihatkan adanya koloni mikroba pada cawan petri . Proses pembuatan pengenceran menggunakan pelarut air banyak akan tetapi konsentrasi ekstrak dari batang greges otot masih tinggi, dengan jumlah yang dihasilkan ini memenuhi standar mutu hal ini dikarenakan ekstrak pada pengenceran $10^{-1}$ masih memiliki konsentrasi tinggi sehingga proses pengenceran menjadi larutan yang pekat sehingga jumlah koloni mikroba pada pengenceran tersebut masih sedikit.

Hasil dalam pengujian cemaran mikroba angka lempeng total yaitu $3,050 \times 10^{4}$ dan $3,5 \times 10^{8}$ ini tidak memenuhi standar mutu. Pencemaran ini terjadi pada pengenceran $10^{-2}$ dan $10^{-}$ 3 dikarenakan kandungan pelarut air lebih banyak ini terjadi pada proses pengenceran terjadi kontaminasi atau kurang steril sehingga proses penyimpananpun kurang baik.

Pengenceran bertujuan untuk menurunkan kadar kepekatan atau tingkat konsentrasi serta memperkecil atau mengurangi jumlah mikroba yang tersuspensi dalam cairan. Tetapi pada penelitian ini dengan semakin banyak pengenceran jumlah koloni mikroba semakin banyak pula, serangkaian percobaan yang telah melakukan sterilisasi. Proses pengenceran ini sangat mempengaruhi karena penggunaan pelarut air.

\section{KESIMPULAN}

Kesimpulan dari penelitian menunjukkan bahwa ekstrak batang greges otot berbentuk ekstrak kental, berwarna hijau dengan bau khas aromatik dan memiliki rasa pahit. Senyawa aktif yang berhasil terdeteksi 
dengan metode KLT adalah flavonoid, alkaloid dan saponin. Parameter non spesifik ekstrak batang greges otot ditandai dengan bobot jenis $0,890 \mathrm{~g} / \mathrm{ml}$, kadar air $10 \%$, dan total cemaran mikroba lebih dari $1 \times 10^{4}$.

\section{DAFTAR PUSTAKA}

Abdillah, R., Eriadi, A dan Khasanah, Y.N., 2018. Aktivitas Antidiare Ekstrak Etanol Herba Greges Otot (Equisentum debileRoxb.) pada Mencit Putih Jatan, Jurnal Farmasi Higea, Sekolah Tinggi Ilmu Farmasi, Padang.

Ali, S., Omer, M.O., Chaudhry, M.A., Ashraf, M., \& Bukhsh, A., 2017, A pharmacological evidence for the presence of antihistamin and anticholinergic activities in Equisetum debile Roxb. Indian journal of pharmacology.

DepKes RI, 1995. Materia Medika Indonesia, Jilid VI, Derektorat Jendral Pengawasan Obat dan Makanan, Jakarta.

DepKes RI, 2000. Parameter Standar Umum Ekstrak Tumbuhan Obat,
Cetakan I, Departemen Kesehatan Republik Indonesia, Jakarta.

Hanani, E., 2016. Analisa Fitokimia, EGC kedokteran, Jakarta

Herbie, T., 2015. Kitab Tanaman Berkhasiat Obat 226 Tumbuhan Obat untuk Penyembuhan Penyakit dan Kebugaran Tubuh, Cetakan I, OCTOPUS Publishing House, Yogyakarta. 